\title{
CORRELATION BETWEEN THE NEONATAL EEG AND THE NEUROLOGICAL EXAMINATION IN THE FIRST YEAR OF LIFE IN INFANTS WITH BACTERIAL MENINGITIS
}

\author{
Adrián Poblano ${ }^{1,2}$, Roberto Gutiérrez ${ }^{2}$
}

\begin{abstract}
Objective: To assess the contribution of neonatal electroencephalogram (EEG) and its correlation with the neurological examination at age of 9 months in newborns with bacterial neonatal meningitis. Method: Twenty seven infants were studied with positive cerebrospinal fluid (CSF) culture for bacteria. We used the worse EEG result during acute phase of meningitis, and performed neurologic follow-up after discharge from hospital. Background cerebral activity was classified as normal or mildly, moderately, or markedly abnormal. Neurologic examination outcomes was classified normal, mild abnormalities, moderate abnormalities and severe abnormalities. Results: EEG performed in the neonatal period during acute bacterial meningitis predicts adverse outcome early at age of 9 months, and had a significant correlation with cephalic perimeter and active tone alterations. Conclusion: Neonatal EEG is useful for predicting abnormal outcomes, especially cephalic perimeter and active tone abnormalities at 9 months of age in infants with bacterial neonatal meningitis.
\end{abstract}

KEY WORDS: bacterial meningitis, electroencephalography, neurophysiologic development, neurologic examination, infants, preterm newborns.

\section{Correlación entre el EEG neonatal y el examen neurológico en el primer año de vida en recién nacidos con meningitis bacteriana}

\begin{abstract}
RESUMEN - Objetivo: Medir la contribución del electroencefalograma (EEG) neonatal y su correlación con el examen neurológico a la edad de 9 meses en recién nacidos con meningitis neonatal bacteriana. Método: Se estudió a 27 neonatos con cultivos positivos de líquido cefalorraquídeo a bacterias. Se uso el peor resultado del EEG obtenido durante el periodo agudo de la meningitis. El seguimiento neurológico se efectuó tras el egreso hospitalario. La actividad de fondo del EEG se clasificó en normal y anormal leve, moderada y severa. El examen neurológico se clasificó en normal, y anormal leve moderado y severo. Resultados: El EEG realizado durante el periodo neonatal durante la fase aguda de la meningitis bacteriana predice bien un resultado adverso a la edad de 9 meses, con correlaciones significativas con el perímetro cefálico y con las alteraciones del tono activo. Conclusion: El EEG neonatal es útil para predecir anormalidades del neurodesarrollo especialmente en el perímetro cefálico y anormalidades del tono durante el primer año de vida en niños que tuvieron meningitis neonatal bacteriana.
\end{abstract}

PALABRAS-CLAVE: meningitis bacteriana, electroencefalografía, examen neurológico, recién nacidos, prematuros.

Newborn infants (especially premature infants) are susceptible to bacterial infections and may develop primary meningitis or suffer a bacterial attack-associated neuroinfection ${ }^{1}$. Bacterial meningitis in newborns infants remains as a serious disease with significant long-term neurological morbidity ${ }^{2-5}$. Prediction of outcome is important in decision-making to provide information to parents, and for identification of subjects requiring close intervention and early fol- low-up. Clinical evaluation includes neurological examination, cerebrospinal fluid (CSF) culture, neuroimaging studies and neurophysiological studies, such as the electroencephalogram (EEG) and evoked potentials.

In the newborn, EEG provides an extremely useful non-invasive test for brain function. The degree of background activity abnormality has proved to be a predictor of long-term neurologic outcome ${ }^{6}$.

Clinic of Sleep Disorders, School of Medicine, National University of Mexico-General Hospital of Mexico and Laboratory of Cognitive Neurophysiology, National Institute for Rehabilitation: ${ }^{1} \mathrm{MD}, \mathrm{MSC}, \mathrm{DSc}$, Neurophysiologist; ${ }^{2} \mathrm{MD}, \mathrm{MSc}$, Rehabilitator.

Received 8 September 2006, received in final form 20 March 2007. Accepted 3 May 2007.

Dr. Adrian Poblano - Dr. Balmis 148 - Colonia Doctores, Delegación Cuauhtémoc - 06720 México City - México. E-mail: drdyslexia@ starmedia.com 
The goal of this study was to assess the contribution of neonatal EEG and its correlation with the neurological examination during the first year of life in clinical follow-up (at age 9 month) of newborns with bacterial neonatal meningitis.

\section{METHOD}

Patients - Subjects were selected from the Neonatal intensive care unit (NICU) at one of the main tertiary-level centers for newborns medical care in Mexico City. All infants with a diagnosis of bacterial meningitis during two years period were identified by review of their medical records. Newborns were included in this study if they met the following criteria: 1) positive CSF culture for bacteria. 2) EEG obtained in the neonatal period during acute phase of meningitis, and 3) neurologic follow-up 9 months after discharge from hospital. The following data were extracted from the infants' medical charts: age and weight at birth, gender, one and five minutes Apgar score ${ }^{7}$, and Silverman-Andersen score in search for respiratory distress ${ }^{8}$, conceptional age at EEG recording, perinatal neurological complications (i.e. asphyxia, intraventricular hemorrhage, coma, seizures), CSF values, bacteria identified in cultures, results of cranial ultrasounds (US), computed tomographic (CT) scans, and neurological examination. This study was approved by the Ethics and Research Committee of the Institute and informed consent was obtained from the newborns' parents.

Electroencephalogram (EEG) - Twelve infants (12/27) were studied by more than one EEG recording. We used the worse EEG results performed during acute phase of disease, during sleep state in the NICU during a session of approximately $45 \mathrm{~min}$ after feeding or until a complete active, slow, and indeterminate sleep cycle was recorded. The scalp was cleaned with alcohol, and impedance of electrodes was always $<5$ kilo-ohms. Recordings were obtained on a digital 22-channel electroencephalograph-polygraph (Nicolet, Madison, WI, USA) and consisted of 16 EEG channels, one electromyogram channel placed on the chin, two channels for left and right eye movements, an additional channel for electrocardiogram (EKG) and two channels for respiration (on nose and chest). Gold cup electrodes were placed with electrolytic paste and head wrapping with tape strips $^{9}$. Bipolar montage was used as follows: F1-F3, F3-C3, C3-P3, P3-O1, F2-F4, F4-C4, C4-P4, P4-O2, F1-F7, F7-T3, T3T5, T5-O1, F2-F8, F8-T4, T4-T6, and T6-O2. Sensitivity was $7.5 \mu \mathrm{V} / \mathrm{mm}$, band pass filters were set between 0.1 and 35 $\mathrm{Hz}$. The infant's behavioral state and all movements of the child during the examination were recorded by the technician and were scored in 30-sec epochs according to Prechtl criteria ${ }^{10}$. Observations included eyes open-closed, eye movements, body movements, jerks and twitches, startling, sucking movements, vocalizations and respiratory irregularities such as sights, pauses and apnea. Careful interpretation was performed off-line. Brain waves present in the EEG were divided into delta $(0.1-3.75 \mathrm{~Hz})$, theta $(4-7.75 \mathrm{~Hz})$, alpha $(8-13 \mathrm{~Hz})$ and beta $(14-35 \mathrm{~Hz})$ rhythms. Brain activ-
Table 1. Classification of EEG abnormalities.

\begin{tabular}{|c|c|}
\hline EEG results & EEG abnormalities \\
\hline $\begin{array}{l}\text { Mildly } \\
\text { abnormal }\end{array}$ & $\begin{array}{l}\text { Normal background with one mild EEG abnor- } \\
\text { mality, or asymmetry, asynchrony, or mild volt- } \\
\text { age depression }\end{array}$ \\
\hline $\begin{array}{l}\text { Moderately } \\
\text { abnormal }\end{array}$ & $\begin{array}{l}\text { Normal background with two or more EEG ab- } \\
\text { normalities, asymmetry, asynchrony mild volt- } \\
\text { age depression with additional abnormality }\end{array}$ \\
\hline $\begin{array}{l}\text { Markedly } \\
\text { abnormal }\end{array}$ & $\begin{array}{l}\text { Burst-suppression, or markedly depression/iso- } \\
\text { electric background activity }\end{array}$ \\
\hline
\end{tabular}

ity was visually and topographically mapped on frontal, central, parietal, occipital and temporal areas, additional details have been published elsewhere ${ }^{11}$. Background cerebral activity was classified according to Klinger et al. ${ }^{12}$ criteria as normal or mildly, moderately, or markedly abnormal (Table 1).

Neurological examination - Infants were examined in the High-Risk Newborns Follow-up Study of Mexico City. Age at examination was corrected at 40 weeks of gestational age in the case of premature infants. Examinations were performed in clinically routine fashion during followup every 3 months during the first year of life by a pediatric neurologist. All examinations were performed with the infant undressed in a warm room in states 3 and 4 according to Prechtl classification ${ }^{10}$. The test included several categories such as: cranial assessment, abnormal eye signs, sensory function, posture and spontaneous motor activity, passive and active tone, primitive and tendon reflexes and postural reactions ${ }^{13}$. The result was considered abnormal when one or more indicators were non-satisfactory. Although Amiel-Tison ${ }^{14}$ warns that neurological examination cannot be quantitatively measured, responses were scored on a 0,1 and 2 scale to compare with results regarding appropriateness for postmenstrual age as optimal response. Outcome was classified as follows: 1) normal, 2) mild abnormalities including abnormalities of tone and excitability but no central nervous system (CNS) depression and no seizures, 3) moderate abnormalities of tone with signs of CNS depression (i.e. minimal monoparesis, controlled seizures, arrested hydrocephalus, poor interaction, hypoactivity, hyporeflexia) and one or two isolated seizures, and 4) severe abnormalities including repeated seizures associated with overt CNS depression (i.e. hemiplegia, quadriplegia, uncontrolled seizures, hydrocephalous).

Data analyses - We calculated $80 \%$ power of detecting differences in means between groups after Chequer et al. ${ }^{15}$ and Klinger et al. ${ }^{12}$ data. We performed descriptive analyses to determine arithmetic mean and standard deviation (SD) for continuous variables and percents for qualitative variables. We conducted analyses of variance test to compare quantitative clinical characteristics between groups of severity of alteration in neonatal EEG, Tukey post-hoc test was used to identify differences between groups. Results between neonatal EEG and neurologic examination 
Table 2. Clinical characteristics of infants with neonatal bacterial meningitis.

\begin{tabular}{lcc}
\hline Characteristic & Mean & SD \\
\hline Age at birth (weeks) & 31.70 & 3.98 \\
Weight at birth (g) & 1504 & 722 \\
Height at birth (cm) & 39.12 & 5.81 \\
Cephalic perimeter (cm) & 29.20 & 4.01 \\
Apgar 1 & 5.44 & 2.25 \\
Apgar 5 & 8.03 & 1.40 \\
Silverman-Andersen & 3 & 1 \\
\hline
\end{tabular}

were compared by $\chi^{2}$ test. We carried-out binomial logistic regression analyses between neonatal EEG results and neurological examination at 3, 6, and 9 months. Alpha value determined for accepted significance a priori was $\leq 0.05$. Neonatal EEG sensitivity and specificity for predicting abnormalities in neurologic examination were calculated from a $2 \times 2$ contingence table ${ }^{16}$.

\section{RESULTS}

Twenty seven patients were studied: average maternal age at the birth of the infant was $27.59 \pm 5.41$ years (range, $17-39$ years). Fourteen mothers (50\%) had one previous gestation, for seven mothers (25\%) it was the first pregnancy, and the remaining mothers had two or more gestations (25\%). Two infants (7\%) were born vaginally and 25 (92\%) by cesarean section.

Fifteen infants were male (55\%) and 12 female $(44 \%)$. Clinical characteristics of infants are shown in Table 2. Fourteen infants $(51 \%)$ were born at age $<32$ weeks of gestation (wG), 10 between 32 and 36 wG $(37 \%)$ and three with 37 or more wG (11\%). Sixteen subjects $(59 \%)$ had birthweight $<1,500 \mathrm{~g}$, eight were between 1501 and $2500 \mathrm{~g}$ (29\%), and three (11\%) infants weighed 2,501 g or more at birth. Height at birth ranged from 26 and $50 \mathrm{~cm}$, while cephalic perimeter had a range of between 24 and $39.3 \mathrm{~cm}$. Apgar score at 1 min (Apgar 1) ranged between 2 and 8 , and 5-min Apgar (Apgar 5) score had a range of between 4 and 9, and Silverman-Andersen score ranged between 5 and 2 .
Bacterial cultures reported Staphylococcus aureus and Staphylococcus coagulase-negative in seven cases of each (25\%). Group B Streptococcus was positive in four subjects (14\%), Group D Streptococcus was positive in two cases (7\%), and different bacteria in each of the seven remaining cases (3\%). Antibiotic treatment included a combination of vancomycin-cephotaxim in 20 subjects (74\%), vancomycine alone in four (14\%) and an ampicillin-amikacin combination in three cases (11\%). Average hospitalization days was $54.4 \pm 29.4$ days with range of 10-120 days.

EEG recordings during neonatal period were normal in nine patients (one third of the sample, 9/27 of patients), while eight were mildly abnormal (8/27), nine were moderately abnormal (9/27), and one was markedly abnormal (1/27). Clinical characteristics comparison of infants by EEG alteration severity detected differences in Apgar 5 score between groups, and post-hoc analyses revealed that infants with moderately and markedly abnormality had significantly lower scores $(p=0.005)$. Neurological examination was performed in 26 infants at 3 and 6 months of age, and in 27 infants at age 9 months; results are show in Table 3.

No statistical differences were found when overall results were compared from both the neurologic examination and neonatal EEG $(p=0.08)$. Significant association was found between neonatal EEG result and cephalic perimeter alteration at 3, 6, and 9 months using normative data from our country ${ }^{17}$ (Wald score $=11.40,9.96$, and 10.42; $p=0.001,0.002$, and 0.001 respectively) and active tone at 9 months (Wald score=8.94; $p=0.003$ ). EEG sensitivity and specificity for predicting change in neurologic examination at 9 months of age were $72 \%$ and $44 \%$ respectively.

CT was performed in two infants and both studies were abnormal, magnetic resonance imaging (MRI) was performed in one patient who had abnormal result. US studies were abnormal in eight subjects $(30 \%)$, abnormalities found included intraventricular hemorrhage in five patients $(18 \%)$, and periven-

Table 3. Neurological examination results (and percentage) in infants with neonatal bacterial meningitis.

\begin{tabular}{|c|c|c|c|c|c|}
\hline \multirow{2}{*}{$\begin{array}{c}\text { Age } \\
\text { (months) }\end{array}$} & \multicolumn{2}{|c|}{ Cephalic perimeter } & \multirow{2}{*}{$\begin{array}{c}\text { Reflexes } \\
\text { (n/ab) }\end{array}$} & \multirow{2}{*}{$\begin{array}{l}\text { Passive tone } \\
\text { (n/ab) }\end{array}$} & \multirow{2}{*}{$\begin{array}{l}\text { Active tone } \\
\text { (n/ab) }\end{array}$} \\
\hline & $(n / a b)$ & $\mathrm{x}(\mathrm{SD}) \mathrm{cm}$ & & & \\
\hline $3(26)$ & $24 / 2$ & $37.3(1.4)$ & $8 / 18$ & $16 / 10$ & $14 / 12$ \\
\hline $6(26)$ & $25 / 1$ & $40.7(1.6)$ & $12 / 14$ & $15 / 11$ & $16 / 10$ \\
\hline $9(27)$ & $23 / 4$ & $42.8(1.7)$ & $13 / 14$ & $17 / 10$ & $22 / 5$ \\
\hline
\end{tabular}

$\mathrm{n}$, normal; ab, abnormal; $\mathrm{x}$, mean; SD, standard deviation; $\mathrm{cm}$, centimeters. 
tricular leukomalacia and hydrocephalous in three subjects each (11\%).

\section{DISCUSSION}

We found that an EEG performed in the neonatal period during acute bacterial meningitis predicts adverse outcome early within the first year of life. Few studies have examined the value of neonatal EEG as a prognostic tool in patients with bacterial neuroinfection.

Watanabe et al. ${ }^{18}$ studied EEG-polygraphically in 29 newborns with meningitis, and visual and auditory evoked potentials were also obtained in some infants: clinical findings correlated with outcomes. EEG background activity was a good prognostic tool but could not indicate complication type, although persistent abnormalities correlated with severe brain injury. Unfortunately, the study included infants without culture-proved meningitis.

Chequer et al. ${ }^{15}$ retrospectively studied 29 infants with culture-proven meningitis; they found that degree of EEG background activity abnormality proved to be a good predictor of long-term neurologic outcome. Infants with normal or mildly abnormal EEG have normal outcomes, whereas those with markedly abnormal EEG died or manifested severe neurologic damage at follow-up.

Klinger et al. ${ }^{12}$ studied 37 infants during the neonatal period and 21 had adverse outcomes; nine died and 12 infants had moderate to severe disability at 1 year of age. EEG background activity and overall EEG description were identified as predictors of adverse outcome; multivariate analysis indicated that the latter was a stronger predictor, with sensitivity of $88 \%$ and specificity of $90 \%$. Infants with normal or mildly abnormal EEG had good outcomes, whereas those with moderate to markedly abnormal EEG died or survived with neurologic sequelae. Our data are in agreement with these latter results, although we found lower values of sensitivity and specificity.

Etiologic agents found in our infants sample are in agreement ${ }^{19}$ and in partial agreement with those of other studies carried out at other NICUs in Mexico $\mathrm{City}^{20}$, but are not in total agreement with other studies performed elsewhere ${ }^{4,21}$. Thus any consideration with regard to differences in neurological outcomes related with specific bacterial agents must be performed carefully, more research is necessary in the future with larger number of patients and with multicenter samples with clinical, neurophysiological, neuroimaging and microbiological techniques to answer this question.
Correlation between EEG results and results concerning cephalic perimeter and active tone on the neurological examination are reported here for the first time and deserve greater attention in future studies. Correlation between Amiel-Tison examination and outcomes with other methods such as US, EEG, and cerebral function monitoring at 12-15 months of age was reported as good. Neurologic examination sensitivity for detecting infants with abnormal US was 0.97 , with EEG 0.89 , and with cerebral function monitoring $0.88^{22}$. Thus combined EEG examination with the clinical Amiel-Tison neurological examination augments probability of detection of early brain damage, as is well know by physicians.

A significant relation between Apgar 5 with severity of EEG abnormalities was found. This finding underlines additive effects of early adverse conditions at birth in infants with CNS infection; this point has been observed in many diseases, such as apnea in infants ${ }^{23}$, and deserve more attention in future research. We suggest that clinicians and investigators must perform a multivariate weighting of each risk-factor, neurological examination, neurophysiologic, and neuroimage studies, for prediction of neurological sequelae in infants with neonatal bacterial meningitis.

Our patients survived during the acute phase of neuroinfection and during the 9-month followup; therefore disease severity could be less than infants in the samples of Watanabe et al. ${ }^{18}$, Chequer et al. ${ }^{15}$, and Klinger et al. ${ }^{12}$ Infants with normal or mildly abnormal EEG survived without sequelae, and those with moderately and markedly abnormal activity were neurologically abnormal at follow-up. EEG abnormalities included an infant with burst-supression, and others with slowing of background activity, spikes and slow waves. Seizures occurred in some of these infants, others had intraventricular bleedingrelated hydrocephalous in which ventriculo-peritoneal shunt placement was performed and were under control during follow-up period.

Our study had certain limitations including small sample size and selection bias, despite the fact that we calculated sufficient statistical power to detect differences among groups of EEG alteration severity ${ }^{24}$. Nonetheless based on the result of this experience it is our recommendation that EEG recording be obtained early in acute phase of the neuroinfection. We conclude that neonatal EEG is useful for predicting abnormalities in cephalic perimeter and active tone at 9 months of age in infants with bacterial neonatal meningitis. 


\section{REFERENCES}

1. Meade RH. Bacterial meningitis in the neonatal infant. Med Clin N Am 1985;69:257-267.

2. Bedford H, de Louvois J, Halket S, Peckham C, Hurley R, Harvey D. Meningitis in infancy in England and Wales: follow-up at age 5 years. BMJ 2001;323:1-5.

3. Jiang ZD, Liu XY, Wu YY, Zheng MS, Liu HC. Long-term impairments of brain and auditory functions of children recovered from purulent meningitis. Dev Med Child Neurol 1990; 32: 473-480.

4. Stevens P, Eames M, Kent A, Halket S, Holt D, Harvey D. Long term outcomes of neonatal meningitis. Arch Dis Child Fetal Neonatal Ed 2003;88:F179-F184.

5. Wheater M, Rennie JM. Perinatal infection is an important risk factor for cerebral palsy in very-low-birthweight infants. Dev Med Child Neurol 2000;42:364-367.

6. Garza-Morales S, Poblano-Luna A. The abnormal electroencephalogram in the newborn (in Spanish). In: Gil-Nagel A, Parra J, Iriarte J, Kanner AM (Eds). Handbook of electroencephalography. Madrid: McGraw Hill-Interamericana, 2002:117-130

7. Apgar V. A proposal for a new method of evaluation of the newborn infant. Curr Res Anesth Analg 1953;32:260-267.

8. Silverman WA, Andersen DH. A controlled clinical trial of effects of water mist and obstructive respiratory signs, death rate and necropsy findings among premature infants. Pediatrics 1956;17:1-10.

9. Hofmann E, Havens B, Geidel S, Hoppenbrouwers T, Hodgman JE. Long-term, continuous monitoring of multiple physiological parameters in newborn and young infants. Acta Paediatr Scand 1977;(Suppl 266):S1-S24.

10. Prechtl HFR. The behavioral states of the newborn (a review). Brain Res 1974;76:185-212.

11. Robles P, Poblano A, Hernández G, Ibarra J, Guzmán I, Sosa J. Cortical, brainstem and autonomic nervous system dysfunction in infants with post-hemorrhagic hydrocephalous. Rev Invest Clin 2002;54:133-138.

12. Klinger G, Chin CN, Otsubo H, Beyene J, Perlman M. Prognostic value of EEG in neonatal bacterial meningitis. Pediatr Neurol 2001;24:28-31.
13. Amiel-Tison C, Grenier A. Evaluation neurologique du noveau-ne et du nourisson. Paris: Masson, 1980.

14. Amiel-Tison C. Update of the Amiel-Tison neurologic assessment for the term neonate or at 40 weeks corrected age. Pediatr Neurol 2002;27: 196-212.

15. Chequer RS, Tharp BS, Dreimane D, Hahn JS, Clancy RR, Coen RW. Prognostic value of EEG in neonatal meningitis: retrospective study of 29 infants. Pediatr Neurol 1992;8:417-422.

16. Dawson-Saunders B, Trapp RG. Basic and clinical biostatistics (in Spanish). Mexico City: Manual Moderno, 1997.

17. Ramos-Galván R. Pediatric somatometry. Follow-up study in infants and children from México City. Arch Invest Med 1975;6(Suppl 1):S83S396.

18. Watanabe K, Hara K, Hakamada S, Kuroyanagi M, Kuno K, Aso K. The prognostic value of EEG in neonatal meningitis. Clin Electroencephalogr 1983;14:67-77.

19. Reyna-Figueroa J, Ortiz-Ibarra FJ, Plazola-Camacho NG, Limón-Rojas AE. Bacterial meningitis in newborns: experience of the National Institute of Perinatology from 1990-1999 (in Spanish). Bol Med Hosp Infant Mex 2004;61:402-411.

20. Rios-Reategui E, Ruiz-Gonzalez L, Murguia-de-Sierra T. Neonatal bacterial meningitis in a third level care unit (in Spanish). Rev Invest Clin 1998;50:31-36.

21. Harvey D, Holt DE, Bedford H. Bacterial meningitis in the newborn: a prospective study of mortality and morbidity. Sem Perinatol 1999;23: 218-225.

22. Paro-Panjan D, Neubauer D, Kodric J, Bratanic B. Amiel-Tison neurological assessment at term age: clinical application, correlation with other methods, and outcome at 12 to 15 months. Dev Med Child Neurol 2005;47:16-26.

23. Poblano A, Márquez A, Hernández G. Apnea in infants. Ind J Pediat 2006;73:1085-1088

24. Browner WS, Black D, Newman TB, Hulley S. Sample size estimates and the power. In Hulley S, Cummings SR (Eds). Clinical research: an epidemiologic approach (in Spanish). Madrid: Harcourt Brace, 1997: 153-165. 